\title{
A Distance Based Method for Solving Multi- objective Optimization Problems
}

\author{
Murshid Kamal \\ Aligarh Muslim University, murshidamu@gmail.com \\ Syed Aqib Jalil \\ Aligarh Muslim University, aqibjali1@gmail.com \\ Syed Mohd Muneeb \\ Aligarh Muslim University, syedmohdmuneeb@gmail.com \\ Irfan Ali \\ Aligarh Muslim University
}

Follow this and additional works at: https://digitalcommons.wayne.edu/jmasm

Part of the Applied Statistics Commons, Social and Behavioral Sciences Commons, and the Statistical Theory Commons

\section{Recommended Citation}

Kamal, Murshid; Jalil, Syed Aqib; Muneeb, Syed Mohd; and Ali, Irfan (2018) "A Distance Based Method for Solving Multi-objective Optimization Problems," Journal of Modern Applied Statistical Methods: Vol. 17 : Iss. 1 , Article 21.

DOI: $10.22237 /$ jmasm/1532525455

Available at: https://digitalcommons.wayne.edu/jmasm/vol17/iss1/21

This Emerging Scholar is brought to you for free and open access by the Open Access Journals at DigitalCommons@WayneState. It has been accepted for inclusion in Journal of Modern Applied Statistical Methods by an authorized editor of DigitalCommons@WayneState. 


\section{EMERGING SCHOLARS}

\section{A Distance Based Method for Solving Multi-Objective Optimization Problems}

\author{
Murshid Kamal \\ Aligarh Muslim University \\ Aligarh, India \\ Syed Mohd Muneeb \\ Aligarh Muslim University \\ Aligarh, India
}

\author{
Syed Aqib Jalil \\ Aligarh Muslim University \\ Aligarh, India \\ Irfan Ali \\ Aligarh Muslim University \\ Aligarh, India
}

A new model for the weighted method of goal programming is proposed based on minimizing the distances between ideal objectives to feasible objective space. It provides the best compromised solution for Multi Objective Linear Programming Problems (MOLPP). The proposed model tackles MOLPP by solving a series of single objective subproblems, where the objectives are transformed into constraints. The compromise solution so obtained may be improved by defining priorities in terms of the weight. A criterion is also proposed for deciding the best compromise solution. Applications of the algorithm are discussed for transportation and assignment problems involving multiple and conflicting objectives. Numerical illustrations are given for the proposed model.

Keywords: Multi-objective optimization, transportation problem, assignment problem, multi-criteria decision making

\section{Introduction}

Multi-objective programming is an approach valid for the analysis of decisions in multi-criteria decision making subject to a set of constraints. Generally, objectives are conflicting in nature, so simultaneous optimization of objectives is impossible. Multi-objective programming deals with trying to obtain a set of efficient or Pareto optimal solutions. This leads decision makers (DMs) to seek a most preferred compromise solution rather than optimal one. During the recent years, multi-

doi: 10.22237/jmasm/1532525455 | Accepted: December 12, 2017; Published: July 25, 2018.

Correspondence: Syed Aqib Jalil, aqibjalil@gmail.com 


\section{KAMAL ET AL}

objective decision making has become a promising field. A multi-objective program can generally be formulated as

$$
\begin{aligned}
& \text { Minimize } F=\left\{\mathrm{f}_{1}(x), \mathrm{f}_{2}(x), \mathrm{f}_{3}(x), \ldots, \mathrm{f}_{M}(x)\right\} \\
& \text { Subject to: } x \in \mathrm{S}, x_{i j} \geq 0
\end{aligned}
$$

where $\mathrm{f}_{i}(i=1,2, \ldots, M)$ are real valued functions of $\mathrm{R}^{n}$ and $\mathrm{S}$ is a non-empty and bounded region included in $\mathrm{R}^{n}$.

The goal programming approach, introduced by Charnes and Cooper (1961), is a useful method for DMs to consider more than one objective (goal) simultaneously, for a compromised and satisfactory solution. An advantage of the goal programming model is that it explicitly introduces the desired target value for each and every criterion. The solution obtained using the goal programming model depends on the weighting method of the different goals. There are two common weighting methods: the first one is the fixed ordering of goals and the second one is the use of weights on goals with the objective of minimizing the weighted sum of goal deviations. The goal programming approach of multi-objective problem has received popularity due to its flexibility in modelling and simplicity in concepts.

In goal programming, it is practical to consider that there are different importance and priorities of different objectives or goals, and a lot of research is done with this problem. Hannan (1981a, 1981b) and Tiwari, Dharmar, and Rao (1987) used the method of evaluation functions to aggregate different goal functions with different weights for different goals. Furthermore, fuzzy goal programming methods (e.g., Tiwari, Dharmar, \& Rao, 1986; H.-K. Chen, 1994) are used when the DM has a priority structure for different goals. These methods have low computational efficiency as many sub problems are solved in sequences. The interactive method was studied (e.g., Rasmy, Lee, El-Wahed, Ragab, \& ElSherbiny, 2002; Sakawa, Kato, \& Nishizaki, 2003), which requires the DM to make important preferences at each step of the optimization process. Romero (2015) discussed issues related to practical goal programming. Perić, Babić, and Rešić (2014) applied goal programming methods for solving the multi-objective fractional linear programming problems under fuzziness. L. Chen, Qiu, Wei, and Shen (2015) proposed a preference-based multi-objective model for the optimization of best management practices. An intuitionistic fuzzy goal programming approach for finding Pareto-optimal solutions to multi-objective programming problems was considered by Razmi, Jafarian, and Amin (2016). 


\section{SOLVING MULTI-OBJECTIVE OPTIMIZATION PROBLEMS}

Different methods were employed to solve Multi-Objective Decision Making (MODM) problems, but goal programming is one of the most studied and efficient methods used to solve these type of problems; the weighted sum method is one of the most used method when the DM has different priorities regarding goals. Although the weighted sum method is an extremely powerful technique for MODM problems, it has advantages and disadvantages. One of its weaknesses is that the DM must specify both goals and their relative importance or weightage which is not always possible. The proposed model tackles this problem by obtaining the best compromise solution when no preferences are given.

\section{Methods for Solving Multi-Objective Optimization Problem}

Solution procedures based on multi-objective optimization problems can be classified basically in two approaches, namely the preference based procedure and the ideal procedure. Preference based procedures are only useful when the preference factors of the objectives are known. Ideal procedures deal with obtaining a wide range of solutions and then selecting one on the basis of information. The methods used for solving multi-objective problems in the literature may be grouped in five categories, namely no preference methods, posteriori methods, priori methods, metaheuristics, and interactive methods:

\section{No-Preference Method}

In No-Preference Methods, the opinions of DMs are not taken into consideration. The multi-objective optimization problem is solved using some relatively simple methods and the solution is presented to DM. The methods in this category include the Method of Global Criterion (e.g., Ringuest \& Rinks, 1987; Miettinen, 1999; Caballero, Luque, Molina, \& Ruiz, 2005) and Proximal Bundle Method (e.g., Kiwiel, 1990; Miettinen \& Mäkelä, 1995).

\section{Posteriori Methods}

A Posteriori Methods may also be called methods of generating Pareto optimal solutions as it deals with finding all or most of the Pareto optimal solutions of a given multi-objective optimization problem. Some methods described in literature are the $\varepsilon$-constrained method (Miettinen \& Mäkelä, 1995; Ehrgott, 2006), Adaptive search method (Miettinen \& Mäkelä, 1995), hybrid method (Chelouah \& Siarry, 2005; Ehrgott, 2006), and the weighting method (Gershon, 1984). 


\section{KAMAL ET AL}

\section{Priori Methods}

Priori Methods DMs must specify priority structure and related opinions before the solution process, unlike the No-Preference Methods. The analyst solves the resulting problem by methods such as goal programming and lexicographic goal programming (Quddoos, Javaid, Ali, \& Khalid, 2013), and present the solution to the DM.

\section{Interactive Methods}

In Interactive Methods the DM works together with an analyst or an interactive computer program. The analyst starts with an initial feasible solution and discusses it with the DM; if the DM is not happy with the current solution, then a new solution or set of new solutions is obtained. Some interactive methods are the Step Method (e.g., Benayoun, De Montgolfier, Tergny, \& Laritchev, 1971; Gardiner \& Steuer, 1994; Miettinen, 1999), Reference Point (RP) Method (Henig \& Ritz, 1986), Sequential Proxy Optimization Technique (SPOT) (Buchanan, 1986), Interactive Surrogate Worth Trade-off (ISWT) Method (Miettinen, 1999), and GeoffrionDyer-Feinberg (GDF) Method (Geoffrion, 1968; Miettinen, 1999).

\section{Some Concepts of Multi-Objective Optimization}

Definition 1. [Weak Pareto Optimal Solution] A solution $x^{*}$ is said to be a weak Pareto optimal solution or a weak efficient solution for the multi-objective optimization problem (1) if and only if there is no $x \in \mathrm{S}$ such that $\mathrm{f}_{i}(x)<\mathrm{f}_{i}\left(x^{*}\right)$ for all $i=1,2, \ldots, n$.

Definition 2. [Pareto Optimal Solution] For a multi-objective optimization problem (1), a solution $x^{*}$ is said to be a Pareto optimal solution or compromise optimal solution if and only if there is no $x \in \mathrm{S}$ such that $\mathrm{f}_{i}(x)<\mathrm{f}_{i}\left(x^{*}\right)$, for all $i=1$, $2, \ldots, n$, for at least one $i$.

Definition 3. [Compromise Solution] A compromise solution of the MOLP is the feasible solution which is preferred by the DM over all other feasible solutions, taking into consideration all criteria contained in the multi-objective functions. 


\section{SOLVING MULTI-OBJECTIVE OPTIMIZATION PROBLEMS}

\section{Proposed Criteria for Best Compromise Solution}

Researchers proposed methods and algorithms to find the best compromise solution such as Hu, Teng, and Li (2007), De and Yadav (2011), Quddoos, Javaid, Ali, and Khalid (2013), El-Wahed and Lee (2006) and Li and Lai (2000). Here the question arises for DMs: what should be the criteria of the best compromise solution? We use the concept of compromise ideal distance and the solution having minimum compromise ideal distance can be considered to be the best compromise solution.

It is impossible to achieve the ideal objectives practically, but they can be represented by a point in Euclidean space. The ideal objective represented in Figure 2 lies outside the feasible region in objective space when objectives are conflicting in nature (see Jones \& Tamiz, 2010).

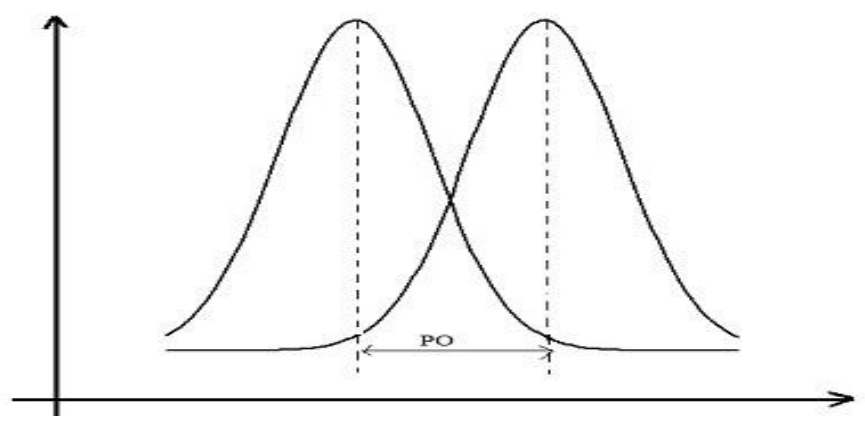

Figure 1. Representation of the region containing the Pareto optimal solution for a biobjective optimization problem

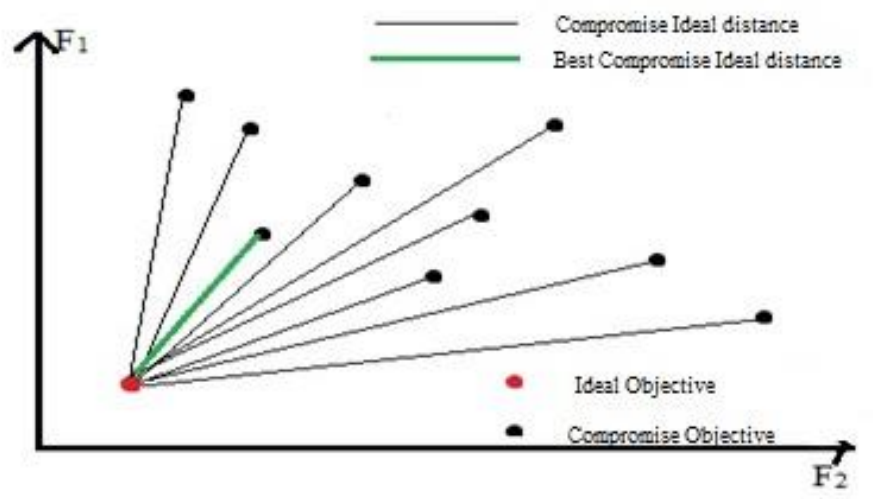

Figure 2. Representation of compromise ideal distances 


\section{KAMAL ET AL}

If the set of ideal solutions is $\left\{\mathrm{f}_{1}^{\text {Ideal }}, \mathrm{f}_{2}^{\text {Ideal }}, \mathrm{f}_{3}^{\text {Ideal }}, \ldots \mathrm{f}_{n}^{\text {Ideal }}\right\}$, which lies in an $n$ dimensional Euclidean space, and the set of objective values for the $i^{\text {th }}$ compromise solution is $\left\{\mathrm{f}_{1}^{* i}, \mathrm{f}_{2}^{* i}, \mathrm{f}_{3}^{* i}, \ldots \mathrm{f}_{n}^{* i}\right\}$ in the feasible objective space, then the compromise ideal distance $D^{\text {Ideal }}$ and best compromise ideal distance $D^{\text {Ideal* }}$ are given by

$$
\begin{aligned}
D_{i}^{\text {Ideal }} & =\sqrt{\left|\mathrm{f}_{1}^{\text {Ideal }}-\mathrm{f}_{1}^{* i}\right|^{2}+\left|\mathrm{f}_{2}^{\text {Ideal }}-\mathrm{f}_{2}^{* i}\right|^{2}+\ldots+\left|\mathrm{f}_{n}^{\text {Ideal }}-\mathrm{f}_{n}^{* i}\right|^{2}} \\
& =\sqrt{\left(\mathrm{f}_{1}^{\text {Ideal }}-\mathrm{f}_{1}^{* i}\right)^{2}+\left(\mathrm{f}_{2}^{\text {Ideal }}-\mathrm{f}_{2}^{* i}\right)^{2}+\ldots+\left(\mathrm{f}_{n}^{\text {Ideal }}-\mathrm{f}_{n}^{* i}\right)^{2}} \\
D^{\text {Ideal } *} & =\operatorname{Min}\left\{D_{i}^{\text {Ideal }}\right\}, \quad i=1,2,3, \ldots, k
\end{aligned}
$$

\section{The Weighted Sum Method}

In the weighted sum method, associate a weighting coefficient to each objective. The multi-objective optimization problem is converted to the single objective optimization problem by minimizing the weighted sum of the objectives, where the weights $w_{i}, \mathrm{i}=1,2, \ldots, M$, corresponding to objective functions satisfy the following conditions:

$$
\sum_{i=1}^{M} w_{i}=1, \quad w_{i} \geq 0, \quad i=1,2, \ldots, M
$$

Let $x_{k}^{(j) *}$ represent the ideal solution for the $j^{\text {th }}$ objective; then solutions $Z_{j}^{*}$ and the objective values may be represented as follows:

$$
\begin{array}{ccccccc}
Z_{1}^{*} & x_{1}^{(1)} & x_{2}^{(1)} & \cdots & x_{h}^{(1)} & \cdots & x_{K}^{(1)} \\
Z_{2}^{*} & \vdots & \vdots & \vdots & \vdots & \vdots & \vdots \\
\vdots & \vdots & \vdots & \vdots & \vdots & \vdots & \vdots \\
Z_{K}^{*} & x_{1}^{(K)} & x_{2}^{(K)} & \cdots & x_{h}^{(K)} & \cdots & x_{K}^{(K)}
\end{array}
$$

Using the weighted sum method, the following normalized single-objective optimization problem is obtained: 


\section{SOLVING MULTI-OBJECTIVE OPTIMIZATION PROBLEMS}

$$
\begin{aligned}
& \text { Minimize } F=\sum_{i=1}^{M} w_{i} \mathrm{f}_{i} \\
& \text { Subject to: } x \in \mathrm{S}, x_{i j} \geq 0
\end{aligned}
$$

where the weights corresponding to objective functions satisfy the conditions described above. Using the above method, single solution points are obtained for different weights that reflect the preferences of the DM.

\section{Additive Model}

In real life multi-objective linear programming (MOLP) problems, some goals have higher priority than the others subject to the set of constraints. The DM may have their own priority structure as per the requirement. The proposed model provides the best compromise solution (i.e., with minimum compromise ideal distance) when no preferences are defined. The DM may also obtain different solutions according to the preferences in terms of the weights assigned to goals in the proposed model.

$$
\begin{aligned}
& \text { Minimize } F=\left\{\mathrm{f}_{1}(x), \mathrm{f}_{2}(x), \mathrm{f}_{3}(x), \ldots, \mathrm{f}_{M}(x)\right\} \\
& \text { Subject to: } x \in \mathrm{S}, x_{i j} \geq 0
\end{aligned}
$$

The proposed model can be implemented easily by starting the first step with obtaining an ideal value for each of the objectives or goals subject to the set of constraints. In the proposed model, we convert the MOLPP into a new single objective transportation problem where the objective is to minimize

$$
\sum_{i=1}^{M}\left|\mathrm{f}_{i}-\mathrm{f}_{i}^{\text {Ideal }}\right|\left(1-w_{i}\right) d
$$

The objective is to minimize the weighted sum of the distances from the ideal objective value to the feasible objective space, where $d$ is the general deviational variable for all objectives and $w_{i}$ is the weight assigned to the $i^{\text {th }}$ objective. Each objective is transformed into constraints with an upper bound of $\mathrm{f}_{i}^{\text {Ideal }}+d\left(1-w_{i}\right)$, where the ideal objective $\mathrm{f}_{i}^{\text {Ideal }}$ is obtained by solving the above linear transportation problem for each objective independently with other objectives. 


\section{KAMAL ET AL}

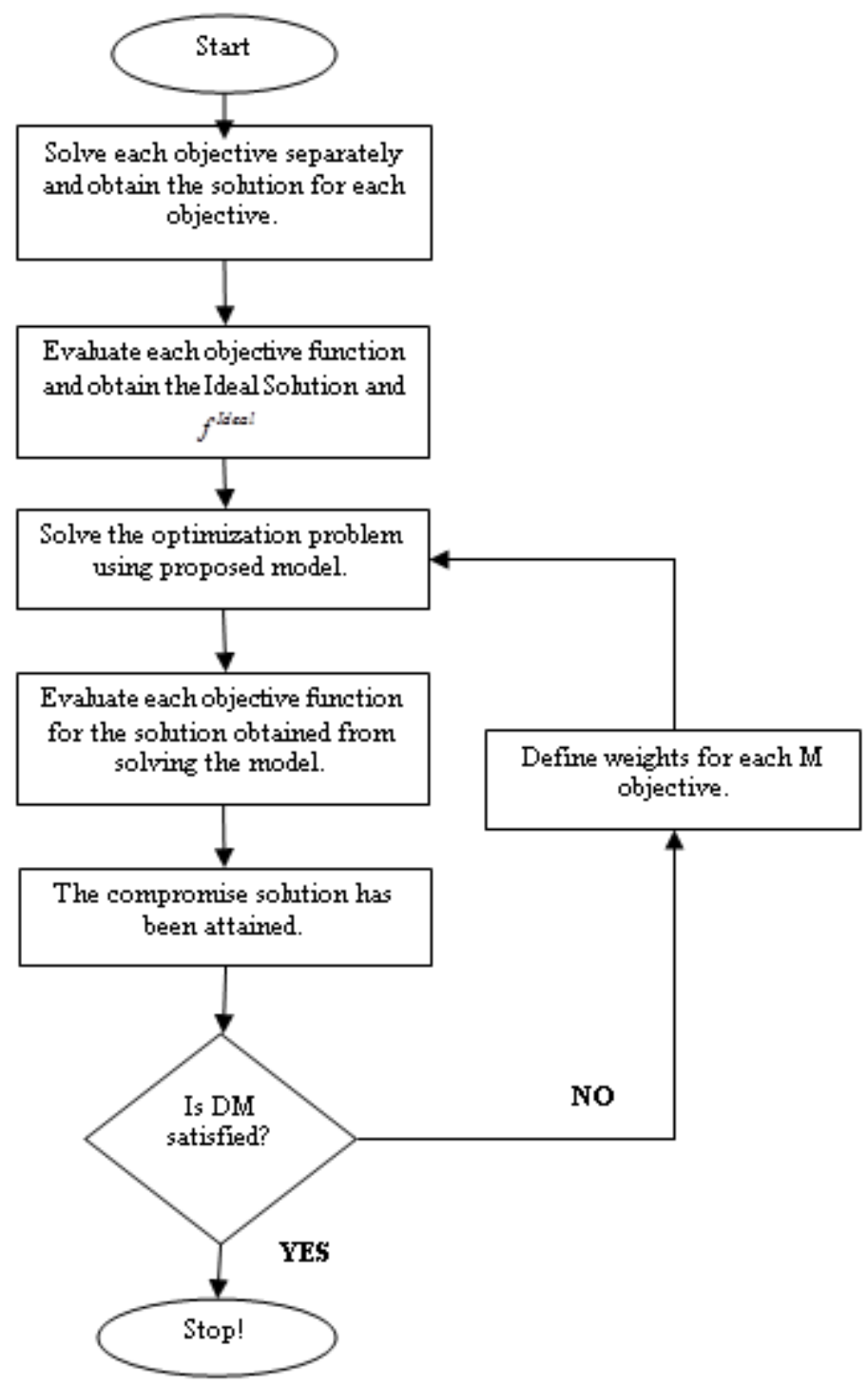

Figure 3. Flow chart representation of the proposed algorithm 


\section{SOLVING MULTI-OBJECTIVE OPTIMIZATION PROBLEMS}

The multi-objective problem (1) simply reduces to the following single objective problem:

$$
\begin{aligned}
& \text { Minimize } F=\sum_{i=1}^{M}\left|\mathrm{f}_{i}-\mathrm{f}_{i}^{\text {Ideal }}\right|\left(1-w_{i}\right) d \\
& \text { Subject to: } \mathrm{f}_{i} \leq \mathrm{f}_{i}^{\text {Ideal }}+d\left(1-w_{i}\right), x \in \mathrm{S}, x_{i j} \geq 0
\end{aligned}
$$

where $w_{i} \in W=\left\{w \in \mathrm{R}^{n} \mid 0 \leq w \leq 1\right\}$, $\mathrm{f}_{i}^{\text {Ideal }}$ is the optimal value of $i^{\text {th }}$ objective obtained as a single objective problem or the ideal value of the $i^{\text {th }}$ objective, and $d$ is the general deviational variable. Larger values of $w_{k}$ in this function will result in smaller values of $d\left(1-w_{i}\right)$ which is required by assigning larger weight so that the objective value may get close to the ideal objective value through added constraints of upper bounds. Figure 3 represents the flow chart representation of the proposed approach:

Step 1. Solve all the $M$ objective functions as single objective linear programming problem ignoring all other objectives subject to the constraints.

Step 2. Evaluate each $M$ objective for their optimal solutions and obtain the Ideal objective value; formulate the multi-objective optimization model as single objective optimization model using the proposed model.

Step 3. Solve the model using any of the available solvers such as $\operatorname{LINGO}^{1}$ (a modelling language and optimizer) or $\mathrm{CPLEX}^{2}$ (optimizer studio).

Step 4. If the DM is satisfied with the solution so obtained then the process terminates, otherwise proceed to next step.

Step 5. Ask DM to define weights for each objective and repeat from Step 3 to Step 5 until the process terminates.

\section{Applications of Proposed Model}

The model is proposed for MOLPP so here we represent the application of above proposed model in multi-objective linear transportation problems (MOLTP). In real world situations, DMs usually face multiple and conflicting objectives and such

\footnotetext{
${ }^{1}$ https://www.lindo.com/downloads/PDF/LINGO.pdf

2 https://www.ibm.com/analytics/data-science/prescriptive-analytics/cplex-optimizer
} 


\section{KAMAL ET AL}

type of transportation problems are called multi-objective transportation problems (MOTPs). In MOTPs the product is to be transported from $m$ sources to $n$ destination points. The cost of transporting a unit form source $i$ to destination $j$ is also denoted as $C_{i j}$, this can be considered to be delivery time, cost of damage, or safety of delivery, etc. A variable $x_{i j}$ represents the unknown quantity to be shipped from source $i$ to destination $j$. Let their capacities be $a_{1}, a_{2}, \ldots, a_{m}$ and $b_{1}, b_{2}, \ldots, b_{n}$, respectively. The objectives are to minimize the total cost of transportation, delivery time, and/or damage cost. Let $\mathrm{f}_{1}, \mathrm{f}_{2}, \ldots, \mathrm{f}_{K}$ be $K$ objectives which are to be minimized. With these assumptions, the MOLTP can be formulated as follows:

$$
\begin{aligned}
& \text { Minimize } F_{k}=\sum_{i=1}^{m} \sum_{j=1}^{n} C_{i j}^{k} x_{i j}, \quad k=1,2,3, \ldots, K \\
& \text { Subject to: } \sum_{i=1}^{n} x_{i j}=a_{i}, \quad i=1,2,3, \ldots, n \\
& \qquad \sum_{j=1}^{m} x_{i j}=b_{j}, \quad j=1,2,3, \ldots, m \\
& x_{i j} \geq 0, i=1,2,3, \ldots, n \text { and } j=1,2,3, \ldots, m
\end{aligned}
$$

To formulate the above MOLTP according to the proposed model, solve the above linear transportation problem for each objective $F_{k}, k=1,2, \ldots, K$, separately. Calculate the value of each objective function for their optimal solutions. Let the obtained optimal values of the $K$ objective functions be $f_{1}^{\text {Ideal }}, f_{2}^{\text {Ideal }}, f_{3}^{\text {Ideal }}, \ldots, f_{K}^{\text {Ideal }}$, let $d$ be the general deviational variable for all objectives, and let $w_{k}$ be the weight assigned to the $k^{\text {th }}$ objective. Then the model is formulated as

$$
\begin{aligned}
& \text { Minimize } F^{\prime}=\sum_{i=1}^{M}\left|f_{k}-f_{k}^{\text {Ideal }}\right|\left(1-w_{i}\right) d \\
& \text { Subject to: } f_{k} \leq f_{k}^{\text {Ideal }}+d\left(1-w_{k}\right), \quad k=1,2, \ldots, K \\
& \qquad \sum_{i=1}^{n} x_{i j}=a_{i}, \quad i=1,2,3, \ldots, n \\
& \qquad \sum_{j=1}^{m} x_{i j}=b_{j}, \quad j=1,2,3, \ldots, m \\
& x_{i j} \geq 0, i=1,2,3, \ldots, n \text { and } j=1,2,3, \ldots, m
\end{aligned}
$$




\section{SOLVING MULTI-OBJECTIVE OPTIMIZATION PROBLEMS}

\section{Numerical Illustration}

Now, consider some numerical examples to illustrate the formulation and solution procedure of the proposed model. For this we have solved a MOTP and a multiobjective assignment problem. The results show that the proposed algorithm gives the best compromise solution with minimum compromise ideal distance.

\section{Example 1}

Consider the following transportation tables associated with a MOTP:

$$
\mathbf{C}_{1}=\left[\begin{array}{llll}
1 & 2 & 7 & 7 \\
1 & 9 & 3 & 4 \\
8 & 9 & 4 & 6
\end{array}\right] \quad \mathbf{C}_{2}=\left[\begin{array}{cccc}
4 & 4 & 3 & 4 \\
5 & 8 & 9 & 10 \\
6 & 2 & 5 & 1
\end{array}\right]
$$

with availability $a_{1}=9, a_{2}=19$, and $a_{3}=17$ and demands $d_{1}=11, d_{2}=3, d_{3}=14$, and $d_{4}=16$. The mathematical programming model of the above problem is written as follows:

Minimize:

$$
\begin{aligned}
& f_{1}=x_{11}+2 x_{12}+7 x_{13}+7 x_{14}+x_{21}+9 x_{22}+3 x_{23}+4 x_{24}+8 x_{31}+9 x_{32}+4 x_{33}+6 x_{34} \\
& f_{2}=4 x_{11}+4 x_{12}+3 x_{13}+3 x_{14}+5 x_{21}+8 x_{22}+9 x_{23}+10 x_{24}+6 x_{31}+2 x_{32}+5 x_{33}+x_{34}
\end{aligned}
$$

Subject to:

$$
\begin{aligned}
& x_{11}+x_{12}+x_{13}+x_{14}=8 \\
& x_{21}+x_{22}+x_{23}+x_{24}=19 \\
& x_{31}+x_{32}+x_{33}+x_{34}=17 \\
& x_{11}+x_{21}+x_{31}=11 \\
& x_{12}+x_{22}+x_{32}=3 \\
& x_{13}+x_{23}+x_{33}=14 \\
& x_{14}+x_{24}+x_{34}=16 \\
& x_{i j} \geq 0, \quad i=1,2,3 \text { and } j=1,2,3,4
\end{aligned}
$$

Obtain the ideal objective values by solving each objective separately; they are found to be 


\section{KAMAL ET AL}

$$
\begin{aligned}
& \mathbf{X}^{1}=\left(\begin{array}{llllllllllll}
5.0 & 3.0 & 0.0 & 0.0 & 6.0 & 0.0 & 0.0 & 13.0 & 0.0 & 0.0 & 14.0 & 3.0
\end{array}\right) \\
& \mathbf{X}^{2}=\left(\begin{array}{llllllllllll}
0.0 & 0.0 & 8.0 & 0.0 & 11.0 & 2.0 & 6.0 & 0.0 & 0.0 & 1.0 & 0.0 & 16.0
\end{array}\right)
\end{aligned}
$$

and the objective values are: $Z_{1}\left(\mathbf{X}^{1}\right)=143, Z_{1}\left(\mathbf{X}^{2}\right)=208, Z_{2}\left(\mathbf{X}^{1}\right)=265$, and $Z_{2}\left(\mathbf{X}^{2}\right)=167$. Here, the ideal values are $f_{1}^{\text {Ideal }}=143$ and $f_{2}^{\text {Ideal }}=167$.

The above problem can be formulated as single objective optimization problem using the proposed model as follows:

Minimize $F=\left(f_{1}-143\right)\left(1-w_{1}\right) d+\left(f_{2}-167\right)\left(1-w_{2}\right) d$

Subject to:

$$
\begin{aligned}
& x_{11}+2 x_{12}+7 x_{13}+7 x_{14}+x_{21}+9 x_{22} \\
& +3 x_{23}+4 x_{24}+8 x_{31}+9 x_{32}+4 x_{33}+6 x_{34} \quad \leq 143+d\left(1-w_{1}\right) \\
& 4 x_{11}+4 x_{12}+3 x_{13}+3 x_{14}+5 x_{21}+8 x_{22} \\
& +9 x_{23}+10 x_{24}+6 x_{31}+2 x_{32}+5 x_{33}+x_{34} \leq 167+d\left(1-w_{2}\right) \\
& x_{11}+x_{12}+x_{13}+x_{14}=8 \\
& x_{21}+x_{22}+x_{23}+x_{24}=19 \\
& x_{31}+x_{32}+x_{33}+x_{34}=17 \\
& x_{11}+x_{21}+x_{31}=11 \\
& x_{12}+x_{22}+x_{32}=3 \\
& x_{13}+x_{23}+x_{33}=14 \\
& x_{14}+x_{24}+x_{34}=16 \\
& x_{i j} \geq 0, \quad i=1,2,3 \text { and } j=1,2,3,4
\end{aligned}
$$

This may be solved by using the LINGO 13.0 package. The compromise solution obtained is as follows:

$$
\mathbf{X}^{*}=\left(\begin{array}{llllllllllll}
2.0 & 3.0 & 3.0 & 0.0 & 9.0 & 0.0 & 10.0 & 0.0 & 0.0 & 0.0 & 1.0 & 16.0
\end{array}\right)
$$

Therefore, $f_{1}^{*}=168$ and if the DM is not satisfied with the solution it is easy to improve the solution by defining weights considering that $\sum_{i=1}^{M} w_{i} \leq 1$. 


\section{SOLVING MULTI-OBJECTIVE OPTIMIZATION PROBLEMS}

Table 1. Compromise objective values corresponding to priorities

\begin{tabular}{rrrrr} 
& Weights assigned & $\boldsymbol{Z}_{1}, \boldsymbol{Z}_{2}$ & $\begin{array}{r}\text { Distance from } \\
\text { ideal solution }\end{array}$ & $\boldsymbol{F}^{\boldsymbol{*}}$ \\
\hline 1 & $W_{1}=0.0, w_{2}=1.0$ & 208,167 & 65.00 & 4225.00 \\
2 & $W_{1}=0.1, w_{2}=0.9$ & 186,171 & 43.18 & 1868.00 \\
3 & $W_{1}=0.2, w_{2}=0.8$ & 176,175 & 33.95 & 1155.00 \\
4 & $W_{1}=0.3, w_{2}=0.7$ & 172,180 & 31.78 & 1048.00 \\
5 & $W_{1}=0.4, w_{2}=0.6$ & 168,185 & 30.80 & 999.00 \\
6 & $W_{1}=0.5, w_{2}=0.5$ & 164,190 & 33.95 & 1012.00 \\
7 & $W_{1}=0.6, w_{2}=0.4$ & 160,195 & 32.75 & 1101.33 \\
8 & $W_{1}=0.7, w_{2}=0.3$ & 156,200 & 35.46 & 1272.86 \\
9 & $W_{1}=0.8, w_{2}=0.2$ & 156,200 & 35.46 & 1885.00 \\
10 & $W_{1}=0.9, w_{2}=0.1$ & 156,200 & 35.46 & 4030.00 \\
11 & $W_{1}=1.0, w_{2}=0.0$ & 143,265 & 98.00 & 9604.00 \\
12 & Without preference & $\mathbf{1 6 8}, \mathbf{1 8 5}$ & $\mathbf{3 0 . 8 0}$ & $\mathbf{9 4 9 . 0 0}$ \\
\hline
\end{tabular}

For different weights or priorities, different solutions can be obtained for Example 1, which are presented in the Table 1. The distance formula $\sqrt{\left(f_{1}^{\text {Ideal }}-f_{1}^{*}\right)^{2}+\left(f_{2}^{\text {Ideal }}-f_{2}^{*}\right)^{2}}$ from coordinate geometry is used for defining the distance of the compromise solution $\left(f_{1}^{*}, f_{2}^{*}\right)$ to the ideal solution $\left(f_{1}^{\text {Ideal }}, f_{2}^{\text {Ideal }}\right)$.

\section{Example 2}

Consider the multi-objective assignment problem taken from De and Yadav (2011) with matrices

$$
\mathbf{C}^{1}=\left[\begin{array}{ccc}
10 & 8 & 15 \\
13 & 12 & 13 \\
8 & 10 & 9
\end{array}\right] \quad \mathbf{C}^{2}=\left[\begin{array}{ccc}
13 & 15 & 8 \\
10 & 20 & 12 \\
15 & 10 & 12
\end{array}\right]
$$

The formulation of the above problem is as follows:

Minimize:

$$
\begin{aligned}
& f_{1}=10 x_{11}+8 x_{12}+15 x_{13}+13 x_{21}+12 x_{22}+13 x_{23}+8 x_{31}+10 x_{32}+9 x_{33} \\
& f_{2}=13 x_{11}+15 x_{12}+8 x_{13}+10 x_{21}+20 x_{22}+12 x_{23}+15 x_{31}+10 x_{32}+12 x_{33}
\end{aligned}
$$




\section{KAMAL ET AL}

Subject to:

$$
\begin{aligned}
& \sum_{i=1}^{3} x_{i j}=1, \quad j=1,2,3 \\
& \sum_{j=1}^{3} x_{i j}=1, \quad i=1,2,3_{21} \\
& x_{i j}=0 \text { or } 1, \quad i=1,2,3 \text { and } j=1,2,3,4
\end{aligned}
$$

Obtain the ideal objective value by solving each objective separately; they are found to be

$$
\begin{aligned}
& x_{12}=1, \quad x_{23}=1, \quad x_{13}=1, \quad x_{21}=1, \quad x_{32}=1 \\
& f_{1}^{\text {Ideal }}=29, \quad f_{2}^{\text {Ideal }}=28
\end{aligned}
$$

This can be formulated as single objective optimization problem using the proposed algorithm as follows:

Minimize:

$$
F=\left(f_{1}-29\right)\left(1-w_{1}\right) d+\left(f_{2}-28\right)\left(1-w_{2}\right) d
$$

Subject to:

$$
\begin{aligned}
& 10 x_{11}+8 x_{12}+15 x_{13}+13 x_{21}+12 x_{22}+13 x_{23}+8 x_{31}+10 x_{32}+9 x_{33} \leq 29+\left(1-w_{1}\right) d \\
& 13 x_{11}+15 x_{12}+8 x_{13}+10 x_{21}+20 x_{22}+12 x_{23}+15 x_{31}+10 x_{32}+12 x_{33} \leq 28+\left(1-w_{1}\right) d \\
& \sum_{i=1}^{3} x_{i j}=1, \quad j=1,2,3 \\
& \sum_{j=1}^{3} x_{i j}=1, \quad i=1,2,3_{21} \\
& x_{i j}=0 \text { or } 1, \quad i=1,2,3 \text { and } j=1,2,3,4
\end{aligned}
$$

Table 2. Compromise objective values corresponding to priorities

\begin{tabular}{rrrrr} 
& Weights assigned & $\boldsymbol{Z}_{1}, \boldsymbol{Z}_{\mathbf{2}}$ & $\boldsymbol{D}^{\text {deal }}$ & $\boldsymbol{x}_{\boldsymbol{i j}}$ \\
\hline 1 & $w_{1}=0.0, w_{2}=1.0$ & 38,28 & 9.00 & $x_{13}=x_{21}=x_{32}=1$ \\
2 & $w_{1}=0.1, w_{2}=0.9$ & 38,28 & 9.00 & $x_{12}=x_{21}=x_{33}=1$ \\
3 & $w_{1}=0.5, w_{2}=0.5$ & 33,35 & 8.06 & $x_{11}=x_{23}=x_{32}=1$ \\
4 & $w_{1}=0.9, w_{2}=0.1$ & 30,37 & 9.05 & $x_{12}=x_{21}=x_{33}=1$ \\
5 & $W_{1}=0.1, w_{2}=0.0$ & 29,42 & 14.00 & $x_{12}=x_{23}=x_{31}=1$ \\
6 & Without preference & $\mathbf{3 3 , 3 5}$ & $\mathbf{8 . 0 6}$ & $x_{11}=x_{23}=x_{32}=1$ \\
\hline
\end{tabular}




\section{SOLVING MULTI-OBJECTIVE OPTIMIZATION PROBLEMS}

The above model is solved by using LINGO 13.0 package. The compromise solution obtained is $x_{11}=1, x_{23}=1$, and $x_{32}=1$; therefore $f_{1}^{*}=33$ and $f_{2}^{*}=35$. If the DM is not satisfied with the solution, it is easy to improve the solution by defining weights considering that $\sum_{i=1}^{M} w_{i} \leq 1$. A set of solutions are obtained in Table 2 for different preferences defined in terms of weights.

\section{Analysis and Comparison of Results}

Consider a MOTP using the proposed model. It is observed that, when no preferences are assigned, the solution obtained is the best compromise solution having minimum compromise ideal distance. For different preferences different compromise solutions are generated which are consistent. Figure 4 clearly represents the consistency of generated solutions for Example 1 as per the weights assigned. A comparison has been made with the proposed model and weighted sum method for the first example in Table 3.

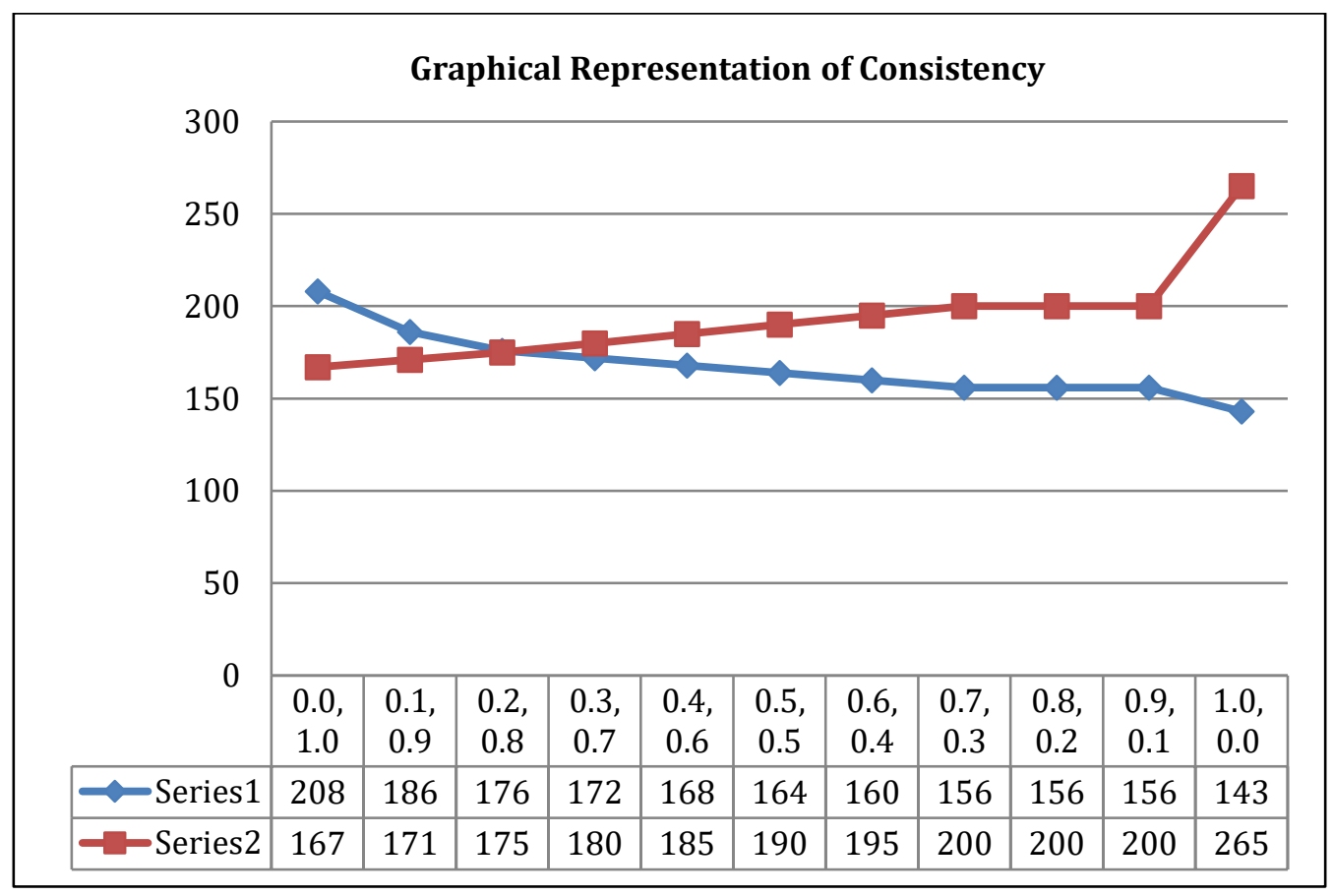

Figure 4. Graphical representation of solutions at different priorities 


\section{KAMAL ET AL}

The solution obtained without preference has the minimum compromise ideal distance. Figure 5 represents the compromise ideal distances for the first example. A comparison has been made with the approaches of Li and Lai (2000), Bit, Biswal, and Alam (1992), Ringuest and Rinks (1987), Quddoos, Javaid, Ali, and Khalid (2013), and Quddoos, Javaid, and Khalid (2013) in Table 4.

Table 3. Comparison of solutions for Example 1 by proposed model and weighted sum method

\begin{tabular}{rrrrrrrr} 
& & \multicolumn{2}{c}{ Proposed method } & & \multicolumn{2}{c}{ Weighted sum method } \\
\cline { 3 - 4 } \cline { 6 - 7 } & Weights assigned & Objectives & Distance & & Objectives & Distance \\
\hline 1 & $W_{1}=0.1, w_{2}=0.9$ & 186,171 & 43.18 & & 208,167 & 65.00 \\
2 & $w_{1}=0.2, w_{2}=0.8$ & 176,175 & 33.95 & & 186,171 & 43.18 \\
3 & $W_{1}=0.3, w_{2}=0.7$ & 172,180 & 31.78 & & 176,175 & 33.95 \\
4 & $W_{1}=0.4, w_{2}=0.6$ & 168,185 & 30.80 & & 176,175 & 33.95 \\
5 & $W_{1}=0.5, w_{2}=0.5$ & 164,190 & 33.95 & & 176,175 & 33.95 \\
6 & $W_{1}=0.6, w_{2}=0.4$ & 160,195 & 32.75 & & 156,200 & 35.46 \\
7 & $W_{1}=0.7, w_{2}=0.3$ & 156,200 & 35.46 & & 156,200 & 35.46 \\
8 & $W_{1}=0.8, w_{2}=0.2$ & 156,200 & 35.46 & & 156,200 & 35.46 \\
9 & $W_{1}=0.9, w_{2}=0.1$ & 156,200 & 35.46 & & 143,265 & 98.00 \\
$\mathbf{1 0}$ & Without preference & $\mathbf{1 6 8 , 1 8 5}$ & $\mathbf{3 0 . 8 0}$ & & -- & -- \\
\hline
\end{tabular}

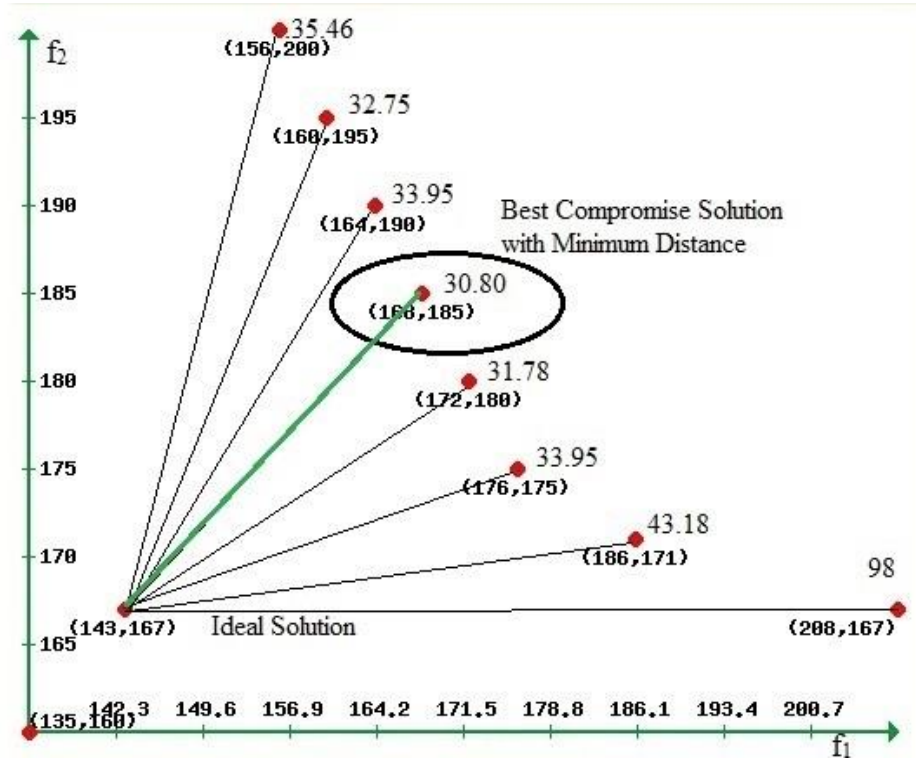

Figure 5. Representation of the compromise ideal distances 


\section{SOLVING MULTI-OBJECTIVE OPTIMIZATION PROBLEMS}

Table 4. Comparison of solutions by five different approaches

\begin{tabular}{rrrrrrr} 
& $\begin{array}{r}\text { Minimize } \\
\text { distance } \\
\text { method }\end{array}$ & $\begin{array}{r}\text { Interactive } \\
\text { approach }^{\text {a }}\end{array}$ & $\begin{array}{r}\text { Fuzzy } \\
\text { programming }_{\text {approach }}\end{array}$ & $\begin{array}{r}\text { Interactive } \\
\text { approach }^{\text {c }}\end{array}$ & $\begin{array}{r}\text { D }_{1} \text { distance } \\
\text { method }^{\text {d }}\end{array}$ & $\begin{array}{r}\text { MMK } \\
\text { method }^{\text {en }}\end{array}$ \\
\hline$f_{1}$ & 168.00 & 168.00 & 160.00 & 156.00 & 184.00 & 176.00 \\
$f_{2}$ & 185.00 & 185.00 & 195.00 & 200.00 & 171.28 & 175.00 \\
$\begin{array}{r}\text { Compromise } \\
\text { ideal distance }\end{array}$ & 30.80 & 30.80 & 32.75 & 35.46 & 41.22 & 33.95 \\
\hline
\end{tabular}

Note: $\quad{ }^{a}$ (El-Wahed \& Lee, 2006); ${ }^{\text {b }}$ (Bit, Biswal, \& Alam, 1992); ${ }^{\text { }}$ (Ringuest \& Rinks, 1987); ${ }^{\text {d }}$ (Quddoos, Javaid, Ali, \& Khalid, 2013); ${ }^{\text {e }(Q u d d o o s, ~ J a v a i d, ~ \& ~ K h a l i d, ~ 2013) ~}$

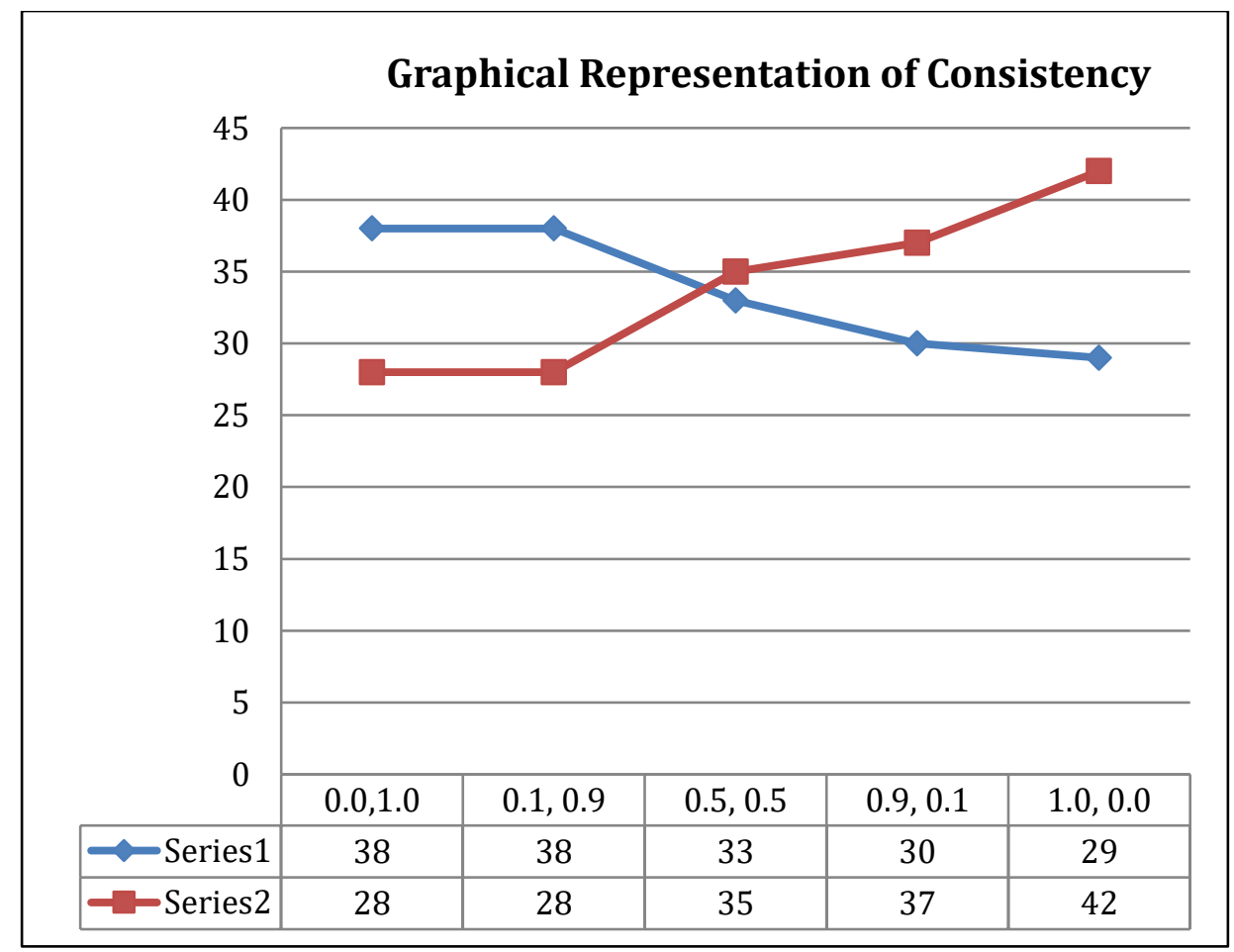

Figure 6. Graphical representation of solutions at different priorities

Now consider the second example of a multi-objective assignment problem using the proposed model. It is observed that, when no preferences are assigned, the solution obtained is the best compromise solution. For different preferences different compromise solutions are generated which are consistent. Figure 6 represents the consistency of generated solutions for Example 2. The solution obtained using proposed model without preference has the minimum compromise 


\section{KAMAL ET AL}

ideal distance. Figure 7 represents the compromise ideal distances obtained for the second example.

\section{Conclusion}

A new model for the weighted sum method is proposed which gives the best compromise solution when DMs have no information regarding relative importance of goals. It can also generate consist compromise solutions in the condition when preferences are defined in terms of weight. The concept of compromise ideal distance is used to decide the best compromise solution when no preferences are defined. The main advantage of the proposed approach over existing approaches is that it can obtain the compromise solution without any preference and for different preferences. The LINGO 13.0 package was used to solve the mathematical models. The proposed model is compared with different existing approaches and it is verified that the proposed model is more suitable for the MOLPP with special reference to transportation and assignment problems.

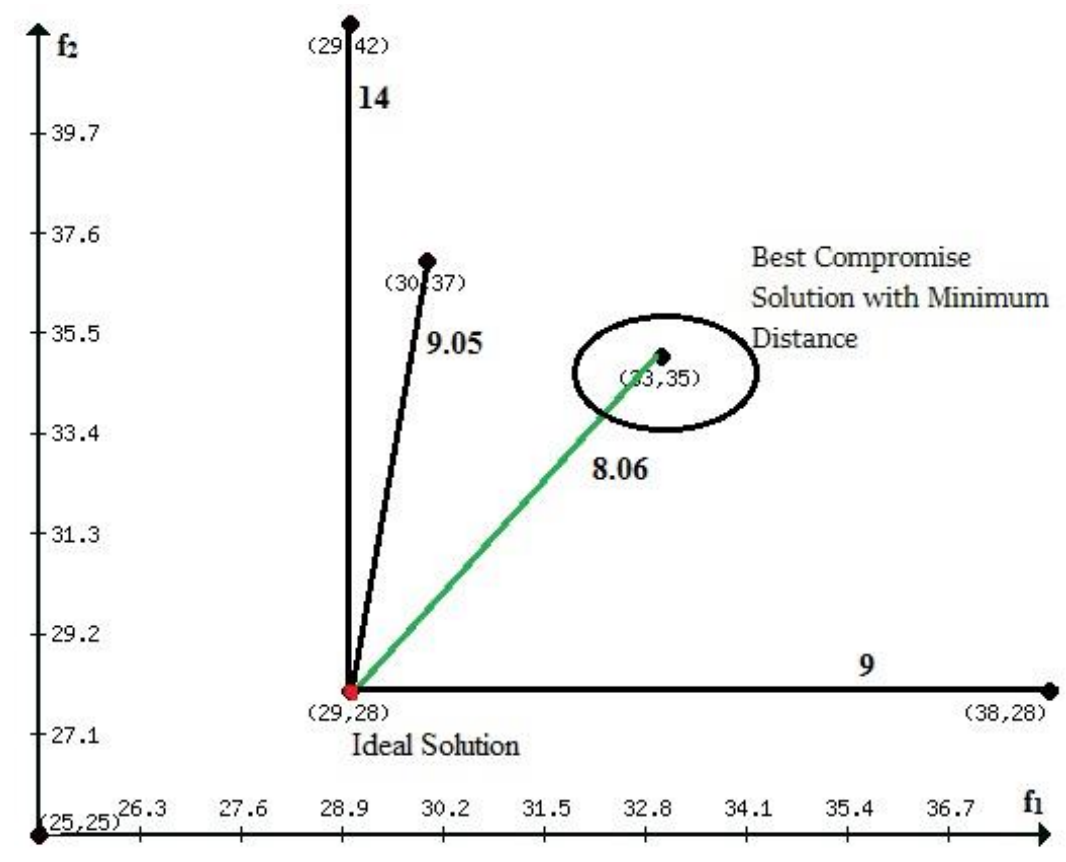

Figure 7. Representation of compromise ideal distances 


\section{SOLVING MULTI-OBJECTIVE OPTIMIZATION PROBLEMS}

\section{References}

Benayoun, R., De Montgolfier, J., Tergny, J., \& Laritchev, O. (1971). Linear programming with multiple objective functions: Step method (stem). Mathematical Programming, 1(1), 366-375. doi: 10.1007/bf01584098

Bit, A. K., Biswal, M. P., \& Alam, S. S. (1992). Fuzzy programming approach to multicriteria decision making transportation problem. Fuzzy Sets and Systems, 50(2), 135-141. doi: 10.1016/0165-0114(92)90212-m

Buchanan, J. T. (1986). Multiple objective mathematical programming: A review. New Zealand Operational Research, 14(1), 1-28. Retrieved from http://www.thebookshelf.auckland.ac.nz/docs/NZOperationalResearch/1986vol14 /Number1/ORSNZ-1986-14-1-01.pdf

Caballero, R., Luque, M., Molina, J., \& Ruiz, F. (2005). MOPEN: A computational package for linear multiobjective and goal programming problems. Decision Support Systems, 41(1), 160-175. doi: 10.1016/j.dss.2004.06.002

Charnes, A., \& Cooper, W. (1961). Management models and industrial applications of goal programming (Vol. 1). New York: Wiley.

Chelouah, R., \& Siarry, P. (2005). A hybrid method combining continuous tabu search and Nelder-Mead simplex algorithms for the global optimization of multiminima functions. European Journal of Operational Research, 161(3), 636654. doi: 10.1016/j.ejor.2003.08.053

Chen, H.-K. (1994). A note on a fuzzy goal programming algorithm by Tiwari, Dharmar, and Rao. Fuzzy Sets and Systems, 62(3), 287-290. doi: 10.1016/0165-0114(94)90112-0

Chen, L., Qiu, J., Wei, G., \& Shen, Z. (2015). A preference-based multiobjective model for the optimization of best management practices. Journal of Hydrology, 520, 356-366. doi: 10.1016/j.jhydrol.2014.11.032

De, P. K., \& Yadav, B. (2011). An algorithm to solve multi-objective assignment problem using interactive fuzzy goal programming approach. International Journal of Contemporary Mathematical Sciences, 6(34), 1651-1662. Retrieved from http://www.m-hikari.com/ijcms-2011/33-36-2011/deIJCMS33-362011.pdf

Ehrgott, M. (2005). Multicriteria optimization (2nd ed.). New York: Springer. doi: 10.1007/3-540-27659-9 


\section{KAMAL ET AL}

El-Wahed, W. F. A. (2001). A multi-objective transportation problem under fuzziness. Fuzzy Sets and Systems, 117(1), 27-33. doi: 10.1016/s01650114(98)00155-9

El-Wahed, W. F. A., \& Lee, S. M. (2006). Interactive fuzzy goal programming for multi-objective transportation problems. Omega, 34(2), 158166.doi: 10.1016/j.omega.2004.08.006

Gardiner, L. R., \& Steuer, R. E. (1994). Unified interactive multiple objective programming. European Journal of Operational Research, 74(3), 391406. doi: 10.1016/0377-2217(94)90219-4

Geoffrion, A. M. (1968). Proper efficiency and the theory of vector maximization. Journal of Mathematical Analysis and Applications, 22(3), 618630. doi: 10.1016/0022-247x(68)90201-1

Gershon, M. (1984). The role of weights and scales in the application of multiobjective decision making. European Journal of Operational Research, 15(2), 244-250. doi: 10.1016/0377-2217(84)90214-5

Hannan, E. L. (1981a). Linear programming with multiple fuzzy goals. Fuzzy Sets and Systems, 6(3), 235-248. doi: 10.1016/0165-0114(81)90002-6

Hannan, E. L. (1981b). On fuzzy goal programming. Decision Sciences, 12(3), 522-531. doi: 10.1111/j.1540-5915.1981.tb00102.x

Henig, M. I., \& Ritz, Z. (1986). Multiplicative decision rules for multiobjective decision problems. European Journal of Operational Research, 26(1), 134-141. doi: 10.1016/0377-2217(86)90165-7

Hu, C.-F., Teng, C.-J., \& Li, S.-Y. (2007). A fuzzy goal programming approach to multi-objective optimization problem with priorities. European Journal of Operational Research, 176(3), 1319-1333. doi:

10.1016/j.ejor.2005.10.049

Jones, D., \& Tamiz, M. (2010). Practical goal programming. New York: Springer. doi: 10.1007/978-1-4419-5771-9

Kiwiel, K. C. (1990). Proximity control in bundle methods for convex nondifferentiable minimization. Mathematical Programming, 46(1-3), 105-122. doi: $10.1007 / \mathrm{bf0} 1585731$

Li, L., \& Lai, K. K. (2000). A fuzzy approach to the multiobjective transportation problem. Computers \& Operations Research, 27(1), 43-57. doi: 10.1016/s0305-0548(99)00007-6

Miettinen, K. M. (1999). Nonlinear multiobjective optimization. Boston, MA: Kluwer Academic Publishers. doi: 10.1007/978-1-4615-5563-6 


\section{SOLVING MULTI-OBJECTIVE OPTIMIZATION PROBLEMS}

Miettinen, K., \& Mäkelä, M. M. (1995). Interactive bundle-based method for nondifferentiable multiobjeective optimization: Nimbus. Optimization, 34(3), 231-246. doi: 10.1080/02331939508844109

Perić, T., Babić, Z., \& Rešić, S. (2014). A goal programming procedure for solving fuzzy multiobjective fractional linear programming problems. Croatian Operational Research Review, 5(2), 401-414. doi: 10.17535/crorr.2014.0022

Quddoos, A., Javaid, S., Ali, I., \& Khalid, M. M. (2013). A lexicographic goal programming approach for a bi-objective transportation problem. International Journal of Scientific \& Engineering Research, 4(7), 24-37. Retrieved from https://www.ijser.org/researchpaper/A-LEXICOGRAPHICGOAL-PROGRAMMING-APPROACH-FOR-A-BI-OBJECTIVETRANSPORTATION-PROBLEM.pdf

Quddoos, A., Javaid, S., \& Khalid, M. M. (2013). A new method to solve bi-objective transportation problem. International Journal of Applied Mathematics, 26(5), 555-563. doi: 10.12732/ijam.v26i5.4

Rasmy, M. H., Lee, S. M., El-Wahed, W. A., Ragab, A. M., \& El-Sherbiny, M. M. (2002). An expert system for multiobjective decision making: application of fuzzy linguistic preferences and goal programming. Fuzzy Sets and Systems, 127(2), 209-220. doi: 10.1016/s0165-0114(01)00201-9

Razmi, J., Jafarian, E., \& Amin, S. H. (2016). An intuitionistic fuzzy goal programming approach for finding Pareto-optimal solutions to multi-objective programming problems. Expert Systems with Applications, 65, 181-193. doi: 10.1016/j.eswa.2016.08.048

Ringuest, J. L., \& Rinks, D. B. (1987). Interactive solutions for the linear multiobjective transportation problem. European Journal of Operational Research, 32(1), 96-106. doi: 10.1016/0377-2217(87)90274-8

Romero, C. (2015). Handbook of critical issues in goal programming. Kent, UK: Elsevier Science.

Sakawa, M., Kato, K., \& Nishizaki, I. (2003). An interactive fuzzy satisficing method for multiobjective stochastic linear programming problems through an expectation model. European Journal of Operational Research, 145(3), 665-672. doi: 10.1016/s0377-2217(02)00150-9

Tiwari, R. N., Dharmar, S., \& Rao, J. R. (1986). Priority structure in fuzzy goal programming. Fuzzy Sets and Systems, 19(3), 251-259. doi: 10.1016/01650114(86)90054-0 


\section{KAMAL ET AL}

Tiwari, R. N., Dharmar, S., \& Rao, J. R. (1987). Fuzzy goal programming An additive model. Fuzzy Sets and Systems, 24(1), 27-34. doi: 10.1016/01650114(87)90111-4 